\title{
Częstość występowania i lekowrażliwość szczepów Propionibacterium acnes izolowanych ze zmian trądzikowych
}

\section{The prevalence and drug sensitivity of Propionibacterium acnes isolated from acne lesions}

\author{
Agata Pruss ${ }^{1 凶}$, Paweł Kwiatkowski ${ }^{1}$, Helena Masiuk ${ }^{1}$, Stefania Giedrys-Kalemba ${ }^{2}$ \\ ${ }^{1}$ Pomorski Uniwersytet Medyczny w Szczecinie, Katedra Mikrobiologii, Immunologii i Medycyny Laboratoryjnej, al. Powstańców Wlkp. 72 , 70-111 Szczecin \\ Pomeranian Medical University in Szczecin, Department of Microbiology, Immunology and Laboratory Medicine \\ ${ }^{2}$ Alab Laboratoria, ul. Stępińska 22/30, 00-739 Warszawa \\ $\triangle$ agata.pruss@pum.edu.pl
}

\begin{abstract}
Introduction: Propionibacterium acnes is one of many pathogens causing the formation of lesions in acne vulgaris, the most common chronic disease of the skin. It affects most adolescents, but can also occur in newborns, and persists in adults. Acne lesions usually occur around the sebaceous glands on the skin of the face, back and chest. Increased resistance of P. acnes to topical antibiotics is a serious medical problem.

The aim of the study was to determine the frequency of $P$. acnes in patients with acne depending on age and sex, and to evaluate drug susceptibility of the isolated strains.

Materials and methods: We analyzed the results of tests performed in 470 outpatients with acne at the age of 9-59 years. The material was a discharge containing pus taken from inflammatory changes of the face (64.3\%), back (7.6\%) and chest (28.1\%). Samples were cultured in anaerobic conditions on Schaedler Agar. The strains were tested for susceptibility to erythromycin,
\end{abstract}

clindamycin, tetracycline and doxycycline, according to the EUCAST standards.

Results: Positive cultures for P. acnes were found in $84.0 \%$ of patients. The highest proportion of positive culture was observed in the age group $21-30$ years old $(91.0 \%)$ and in $>50$ years $(88.2 \%)$, the lowest in patients aged $31-40$ (78.2\%). P. acnes was isolated more often in men $(86.1 \%)$ than in women $(81.7 \%)$. All isolates showed sensitivity to doxycycline, and only $1.5 \%$ were resistant to tetracycline. A statistically significant $(\mathrm{p} \leq 0.05)$ increase of resistance to erythromycin and clindamycin, from $29.6 \%$ in 2010 to $48.7 \%$ in 2014 , was observed.

Conclusions: Acne lesions are increasingly observed in adults $>21$ years old. The prevalence of acne in women and men is comparable. P. acnes strains show good sensitivity to tetracyclines, but the increased resistance to erythromycin and clindamycin is alarming.

Keywords: Propionibacterium acnes; drug susceptibility; acne.

\begin{abstract}
ABSTRAKT
Wstęp: Propionibacterium acnes jest patogenem współodpowiedzialnym za tworzenie się zmian chorobowych w trądziku pospolitym, najczęstszej przewlekłej chorobie skóry. Dotyka ona w większości osób w okresie dojrzewania, może występować także u noworodków oraz utrzymywać się u osób dorosłych. Zmiany chorobowe występują zwykle w okolicy gruczołów łojowych na skórze twarzy i pleców, rzadziej klatki piersiowej. Obecnie największym problemem jest narastanie oporności szczepów na antybiotyki stosowane miejscowo.

Celem pracy było określenie częstości występowania P. acnes u pacjentów ze zmianami trądzikowymi w zależności od wieku i płci oraz ocena lekowrażliwości izolowanych szczepów.

Materiały i metody: Przeanalizowano wyniki badań wykonanych u 470 pacjentów ambulatoryjnych w wieku 9-59 lat ze zmianami trądzikowymi. Materiał stanowiła wydzielina ropna pobrana ze zmian zapalnych na twarzy $(64,3 \%)$, pleców $(7,6 \%)$ oraz klatki piersiowej $(28,1 \%)$. Wymazy posiewano na podłoże Schaedler Agar z dodatkiem 5\% krwi baraniej i inkubowano
\end{abstract}

\section{WSTĘP}

Propionibacterium acnes to małe Gram-dodatnie, beztlenowe pałeczki, które charakteryzują się zdolnością fermentacji węglowodanów i produkcją kwasu propionowego. w warunkach beztlenowych. Wrażliwość wyizolowanych szczepów na erytromycynę, klindamycynę, tetracyklinę i doksycyklinę oceniano zgodnie z wytycznymi EUCAST.

Wyniki: Dodatnie wyniki posiewów w kierunku P. acnes stwierdzono u 84,0\% pacjentów. Najwyższy odsetek posiewów dodatnich uzyskano w grupie wiekowej 21-30 lat $(91,0 \%)$ i > 50. r.ż. $(88,2 \%)$, najniższy u osób w wieku $31-40$ lat $(78,2 \%)$. P. acnes częściej izolowano u mężczyzn $(86,1 \%)$ niż u kobiet $(81,7 \%)$. Wszystkie wyizolowane szczepy $P$. acnes były wrażliwe na doksycyklinę, jedynie 1,5\% izolatów wykazało oporność na tetracyklinę. Odnotowano istotny statystycznie $(\mathrm{p} \leq 0,05)$ wzrost oporności na erytromycynę i klindamycynę, z 29,6\% w 2010 r. do 48,7\% w 2014 r. Wnioski: Zmiany trądzikowe coraz częściej obserwuje się u osób dorosłych >21. r.ż. Zapadalność na trądzik u kobiet i mężczyzn jest porównywalna. Szczepy P. acnes wykazują dobrą wrażliwość na tetracykliny, natomiast niepokojąco narasta oporność na erytromycynę i klindamycynę.

Słowa kluczowe: Propionibacterium acnes; lekowrażliwość; trądzik.

Drobnoustroje te wchodzą w skład flory fizjologicznej skóry i przewodu pokarmowego, mogą kolonizować błony śluzowe dróg rodnych kobiet. Są także patogenem współodpowiedzialnym za tworzenie się zmian chorobowych w trądziku pospolitym, najczęstszej przewlekłej chorobie skóry. 
Nie obserwuje się większych zależności dotyczących płci, jednakże u mężczyzn występuje cięższa postać zakażenia [1]. Zmiany chorobowe występują zwykle w okolicy gruczołów łojowych na skórze twarzy i pleców, rzadziej klatki piersiowej [2]. W powstawaniu trądziku bierze udział szereg czynników. W wyniku zmian hormonalnych dochodzi do zwiększonej produkcji łoju i rogowacenia ujść mieszków włosowych, a następnie zaczopowania gruczołów łojowych. Sprzyja to namnażaniu się bakterii beztlenowych, głównie P. acnes. Bakterie te, dzięki wytwarzaniu lipaz, rozkładają triglicerydy do wolnych kwasów tłuszczowych, co w konsekwencji prowadzi do powstawania charakterystycznych dla trądziku nacieków zapalnych w obrębie gruczołów łojowych [3].

Klasyfikacja trądziku jest skomplikowana i zależy głównie od stopnia nasilenia zmian skórnych, a także od czynników wywołujących wykwity. Według Polskiego Towarzystwa Dermatologicznego, biorąc pod uwagę przewagę poszczególnych wykwitów, trądzik można podzielić na zaskórnikowy, grudkowo-krostkowy, ropowiczy lub bliznowcowy. Dodatkowy podział jest związany z przebiegiem choroby, a więc mówi się o trądziku łagodnym, umiarkowanym lub ciężkim [4]. Profesjonalna ocena i odpowiednie zakwalifikowanie zmian trądzikowych jest bardzo przydatne w określeniu efektów terapeutycznych.

Postępowanie lecznicze zależy przede wszystkim od stanu zaawansowania zmian skórnych. Polega głównie na łagodzeniu i likwidacji objawów choroby, a także zapobieganiu powstawania blizn potrądzikowych. W większości przypadków stosuje się leczenie miejscowe, mające na celu ograniczenie rogowacenia ujść mieszków włosowych, zahamowanie namnażania P. acnes oraz likwidację łojotoku. W tym rodzaju terapii najczęściej wykorzystuje się retinoidy, nadtlenek benzoilu, kwas azelainowy oraz antybiotyki. Spośród antybiotyków najczęściej rekomendowane są erytromycyna oraz klindamycyna, które znacznie ograniczają stan zapalny i wpływają na zmniejszenie kolonizacji P. acnes [5]. Ze względu na narastającą oporność drobnoustrojów leki te nie powinny być stosowane w monoterapii, lecz w połączeniu z innymi preparatami, np. nadtlenkiem benzoilu. W cięższych przypadkach trądziku konieczne jest leczenie ogólne polegające na doustnym podaniu antybiotyku i retinoidu, a u kobiet po 20. r.ż. z nasilonymi zmianami chorobowymi na leczeniu hormonalnym. Antybiotykiem z wyboru jest tetracyklina lub doksycyklina. W przypadku nietolerancji na te antybiotyki, u kobiet w ciąży, karmiących i dzieci do lat12 stosuje się makrolidy [6]. Leczenie antybiotykiem nie powinno trwać dłużej niż przez 3-6 miesiące, a po 6-8 tygodniach można dokonać wstępnej oceny skuteczności terapii.

Celem pracy było określenie częstości występowania P. acnes u pacjentów ze zmianami trądzikowymi w zależności od wieku i płci oraz ocena lekowrażliwości izolowanych szczepów.

\section{MATERIAtY I METODY}

Analizie poddano wyniki badań mikrobiologicznych wykonanych u 470 pacjentów ambulatoryjnych ze zmianami trądzikowymi w wieku 9-59 lat. Badania były przeprowadzone w Katedrze i Zakładzie Mikrobiologii i Immunologii Pomorskiego Uniwersytetu Medycznego w Szczecinie w latach 2010-2014. Materiał stanowiła wydzielina ropna pobrana ze zmian zapalnych skóry twarzy (302 badania), pleców (36) oraz klatki piersiowej (132), którą posiewano na podłoże Schaedler Agar z dodatkiem 5\% krwi baraniej (bioMérieux, Polska). Inkubację prowadzono 3-5 dni w temperaturze $35-37^{\circ} \mathrm{C} w$ atmosferze beztlenowej. Identyfikację przeprowadzano na podstawie oceny cech morfologicznych kolonii, komórek barwionych metodą Grama i testu biochemicznego ANC Vitek 2 Compact (bioMérieux, Polska).

Wrażliwość na erytromycynę, klindamycynę, tetracyklinę i doksycyklinę określono dla wszystkich wyizolowanych szczepów P. acnes zgodnie z wytycznymi Europejskiego Komitetu ds. Oznaczania Lekowrażliwości (EUCAST) z wykorzystaniem podłoża Brucella Agar (bioMérieux, Polska) [7].

$\mathrm{W}$ analizie statystycznej zastosowano test $\chi^{2}$ oraz test Fishera (dwustronny) z wykorzystaniem programu statystycznego Statistica (wersja 12.0). Jako poziom istotności przyjęto $\mathrm{p} \leq 0,05$.

\section{WYNIKI}

Badania wydzieliny ropnej ze zmian trądzikowych wykonano u 470 osób. P. acnes wyizolowano od 395 pacjentów, co stanowi $84,0 \%$. Wyodrębniono 6 grup wiekowych: $\leq 10$. r.ż. $(\mathrm{n}=8), 11-20$ lat ( $\mathrm{n}=106), 21-30$ lat $(\mathrm{n}=166), 31-40$ lat $(\mathrm{n}=110), 41-50$ lat $(\mathrm{n}=46),>50$. r.ż. $(\mathrm{n}=34)$. Większość badanych $(35,3 \%)$ należała do grupy wiekowej 21-30 lat. W tej grupie oraz u osób >50. r.ż. zaobserwowano najwyższy odsetek posiewów dodatnich, odpowiednio 91,0\% i 88,2\%. Najniższy odsetek odnotowano w przypadku grupy 31-40 lat (78,2\%), natomiast u osób $\leq 10$. r.ż. nie uzyskano posiewów dodatnich. Istotne statystycznie różnice stwierdzono w grupie wiekowej $\leq 10$. r.ż. $(\mathrm{p}<0,001)$ oraz w grupie 21-30 lat ( $p=0,003)$. Szczegółowe dane przedstawiono $w$ tabeli 1.

Wśród osób badanych mężczyźni stanowili większy odsetek (53,4\%) niż kobiety $(46,6 \%)$. Także u mężczyzn częściej izolowano ze zmian trądzikowych P. acnes $(86,1 \%)$ niż u kobiet $(81,7 \%)$, jednakże wyniki te nie były istotne statystycznie - tabela 2 .

Występowanie P. acnes w grupach wiekowych w zależności od płci przedstawiono w tabeli 3. Różnice istotne statystycznie stwierdzono jedynie w przypadku kobiet w grupie wiekowej 21-30 lat $(p=0,027)$ oraz 31-40 lat $(p=0,028)$.

P. acnes ze zmian zapalnych w trądziku częściej izolowano ze skóry pleców - w 94,4\% (34 z 36) niż ze skóry klatki piersiowej - 84,8\% (112 ze 132) i twarzy 82,5\% (249 z 302), aczkolwiek nie są to różnice istotne statystycznie. Wyniki przedstawiono na rycinie 1.

Wrażliwość na antybiotyki określono dla 395 wyizolowanych w latach 2010-2014 szczepów P. acnes. Wszystkie szczepy wykazywały wrażliwość na doksycyklinę, 98,2\% było wrażliwych na tetracyklinę, 95,7-100\% w poszczególnych latach. Odnotowano jedynie $6(1,5 \%)$ szczepów opornych na tetracyklinę i 1 średnio wrażliwy. Odsetek szczepów wrażliwych i opornych na erytromycynę i klindamycynę kształtował się identycznie w kolejnych latach, średnio $62,5 \%$ było wrażliwych, 
TABELA 1. Występowanie Propionibacterium acnes w zależności od grupy wiekowej

\begin{tabular}{lccc}
\multirow{2}{*}{$\begin{array}{c}\text { Grupa } \\
\text { wiekowa } \\
\text { w latach }\end{array}$} & $\begin{array}{c}\text { Propionibacterium acnes } \\
\text { posiew dodatni } \\
\text { n (\%) }\end{array}$ & $\begin{array}{c}\text { posiew ujemny } \\
\text { n (\%) }\end{array}$ & $\begin{array}{c}\text { Razem } \\
\text { n (\%) }\end{array}$ \\
\cline { 2 - 3 }$\leq 10$ & $0(0,0)^{*}$ & $8(100,0)$ & $8(100,0)$ \\
\hline $11-20$ & $90(84,9)$ & $16(15,0)$ & $106(100,0)$ \\
\hline $21-30$ & $151(90,9)^{*}$ & $15(9,0)$ & $166(100,0)$ \\
\hline $31-40$ & $86(78,1)$ & $24(21,8)$ & $110(100,0)$ \\
\hline $41-50$ & $38(82,6)$ & $8(17,3)$ & $46(100,0)$ \\
\hline$>50$ & $30(88,2)$ & $4(11,7)$ & $34(100,0)$ \\
\hline Razem & $395(84,0)$ & $75(16,0)$ & $470(100,0)$ \\
\hline
\end{tabular}

* różnice istotne statystycznie

TABELA 2. Występowanie Propionibacterium acnes u pacjentów ze względu na płeć

\begin{tabular}{lccc} 
& \multicolumn{2}{c}{ Propionibacterium acnes } & \\
\cline { 2 - 3 } Płeć & $\begin{array}{c}\text { posiew dodatni } \\
\mathbf{n}(\%)\end{array}$ & $\begin{array}{c}\text { posiew ujemny } \\
\mathbf{n}(\%)\end{array}$ & Razem \\
\hline Męska & $216(86,1)$ & $35(13,9)$ & $251(100,0)$ \\
\hline Żeńska & $179(81,7)$ & $40(18,3)$ & $219(100,0)$ \\
\hline Razem & $395(84,0)$ & $75(16,0)$ & $470(100,0)$ \\
\hline
\end{tabular}

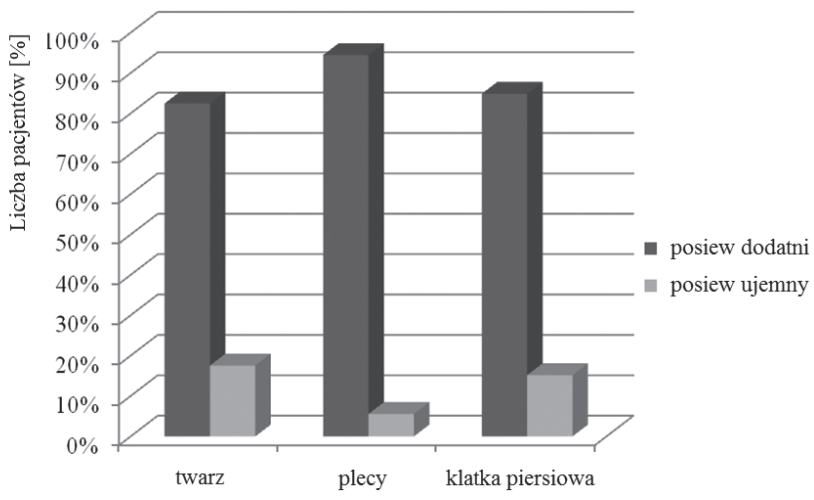

RYCINA 1. Miejsce izolacji Propionibacterium acnes

$37,7 \%$ opornych, natomiast nie odnotowano szczepów średnio wrażliwych - tabela 4. Zaobserwowano jednak istotny statystycznie wzrost oporności, z 29,6\% w 2010 r. do 48,7\% w 2014 r. $(p=0,037)$.

\section{DYSKUSJA}

Pomimo że P. acnes należy do stałej mikrobioty zdrowej skóry człowieka, udowodniono, iż drobnoustroje te biorą udział w najważniejszych procesach powstawania trądziku: rozwoju stanu

TABELA 3. Występowanie Propionibacterium acnes w grupach wiekowych w zależności od płci

\begin{tabular}{|c|c|c|c|c|c|c|}
\hline \multirow{2}{*}{$\begin{array}{c}\text { Grupa wiekowa } \\
\text { w latach }\end{array}$} & \multicolumn{3}{|c|}{ Mężczyźni } & \multicolumn{3}{|c|}{ Kobiety } \\
\hline & $\begin{array}{c}\text { posiew dodatni } \\
\mathrm{n}(\%)\end{array}$ & $\begin{array}{c}\text { posiew ujemny } \\
\mathrm{n}(\%)\end{array}$ & $\begin{array}{c}\text { razem } \\
\mathrm{n}(\%)\end{array}$ & $\begin{array}{c}\text { posiew dodatni } \\
\mathrm{n}(\%)\end{array}$ & $\begin{array}{c}\text { posiew ujemny } \\
\mathrm{n}(\%)\end{array}$ & $\begin{array}{c}\text { razem } \\
\mathrm{n}(\%)\end{array}$ \\
\hline 11-20 & $48(88,9)$ & $6(11,1)$ & $54(100,0)$ & $42(80,8)$ & $10(19,2)$ & $52(100,0)$ \\
\hline 21-30 & $80(90,9)$ & $8(9,1)$ & $88(100,0)$ & $71(91,0)^{*}$ & $7(36,4)$ & $78(100,0)$ \\
\hline $31-40$ & $46(82,1)$ & $10(17,9)$ & $56(100,0)$ & $40(74,1)^{*}$ & $14(25,9)$ & $54(100,0)$ \\
\hline$>50$ & $17(85,0)$ & $3(15,0)$ & $20(100,0)$ & $13(92,9)$ & $1(7,1)$ & $14(100,0)$ \\
\hline Razem & $216(87,1)$ & $32(12,9)$ & $248(100,0)$ & $179(83,6)$ & $35(16,4)$ & $214(100,0)$ \\
\hline
\end{tabular}

* różnice istotne statystycznie

TABELA 4. Lekowrażliwość szczepów Propionibacterium acnes w zależności od roku badania

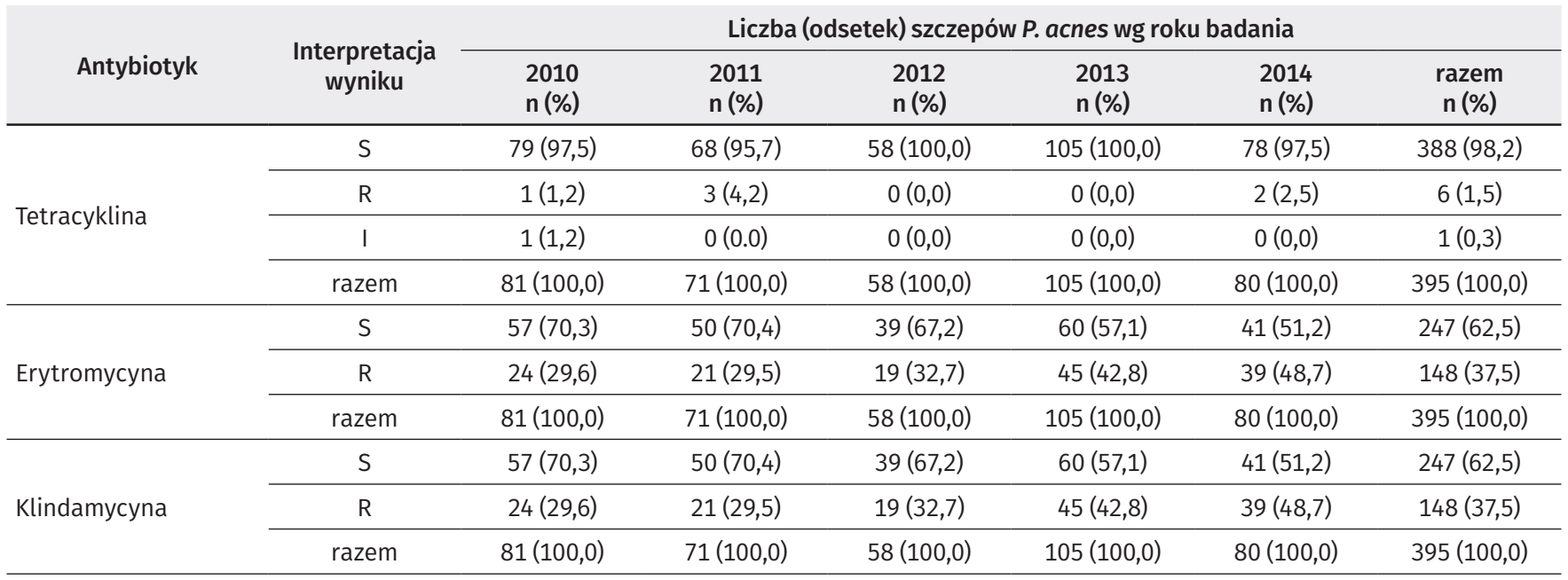

S - szczepy wrażliwe; R - szczepy oporne; I - szczepy średnio wrażliwe 
zapalnego, zaburzeniach produkcji łoju i keratynizacji. Poprzez stymulację szlaków wrodzonej i nabytej odpowiedzi immunologicznej bakterie te przyczyniają się do procesu zaburzenia rogowacenia i proliferacji keratynocytów, co z kolei sprzyja tworzeniu się zaskórników [8].

Trądzik pospolity dotyka głównie osób między 11. a 30. r.ż., z czego ponad połowa przypadków przebiega łagodnie. Stopień ciężkości tej dermatozy zależy od wieku pacjentów i ich dojrzałości płciowej [9]. Coraz częściej obserwuje się rozwój zmian trądzikowych jeszcze przed okresem pokwitania [10], aczkolwiek w badaniach własnych u 8 pacjentów $\leq 10$. r.ż. nie wyizolowano $P$. acnes ze zmian skórnych. Badania Goodmana wykazały występowanie trądziku u 95-100\% 16-17-letnich chłopców i 83-85\% dziewcząt [11]. Z kolei Mendoza i wsp. obecność zmian trądzikowych obserwowali u 53\% badanych mężczyzn i $47 \%$ kobiet [12]. Podobnie w badaniach własnych mężczyźni stanowili większy odsetek $(53,4 \%)$ niż kobiety $(46,6 \%)$, także dodatnie posiewy w kierunku P. acnes stwierdzono częściej u mężczyzn $(86,1 \%)$ niż u kobiet $(81,7 \%)$.

Pomimo że trądzik zwykle uznawany był za problem natury hormonalnej dorastającej młodzieży, to od kilkunastu lat coraz częściej obserwuje się tę dermatozę u osób dorosłych. Najwyższą zapadalność na trądzik Poli i wsp. stwierdzili między 14. a 17. r.ż. u osób płci żeńskiej i między 16. a 19. r.ż. u płci męskiej, natomiast średnia wieku pacjentów z utrzymującymi się zmianami trądzikowymi wzrosła z 20,5. do 24.-26. r.ż. [13]. Khunger i Kumar obserwowali trądzik u 73,2\% osób >25. r.ż. [14]. W badaniach przeprowadzonych przez Gouldena i wsp. u osób $>25$. r.ż. ze zmianami skórnymi o etiologii P. acnes odsetek kobiet wynosił 54\%, zaś mężczyzn 40\% [15]. Collier i wsp. podają 42,5\% mężczyzn i 50,9\% kobiet z utrzymującymi się zmianami trądzikowymi w grupie >20. r.ż., 20,1\% mężczyzn i 35,4\% kobiet w grupie ok. 30. r.ż., a u osób >40. r.ż. odpowiednio 12\% i 26,3\% [16]. McConnell i wsp. wykazali 10\% osób z trądzikiem między 35. a 44. r.ż. [17]. Z kolei Collier i wsp. obserwowali trądzik u 7,3\% mężczyzn i 15,3\% kobiet >50. r.ż. [16]. W badaniach własnych najliczniejszą grupą ze zmianami trądzikowymi były osoby między 21. a 30. r.ż. (35,3\%); w tej grupie uzyskano także najwyższe odsetki dodatnich posiewów w kierunku, P. acnes 90,9\% u mężczyzn i 91\% u kobiet. W pozostałych, mniej licznych grupach wiekowych, $P$. acnes wykazano w nieco mniejszych odsetkach $(78,1-88,2 \%)$, podobnie u mężczyzn $(82,1-88,9 \%)$, jak i u kobiet $(80,8-92,9 \%)$.

Coraz częstsze występowanie/utrzymywanie się trądziku u osób dorosłych może być związane m.in. ze stresującym trybem życia, nieodpowiednią dietą czy też uwarunkowaniami genetycznymi. Opublikowano szereg prac wskazujących na występowanie trądziku późnego, zwłaszcza u kobiet. Dumont-Wallon i Dréno sugerują, iż jest to związane ze zmianami hormonalnymi i przetrwałą formą trądziku młodzieńczego [18]. Podobne wnioski wyciągnęli Rivera i Guerra na podstawie badań przeprowadzonych w grupie hiszpańskich pacjentek, a także Szczurek i wsp. oceniający częstość występowania trądziku późnego u młodych kobiet i jego wpływ na jakość życia $[19,20]$. We własnej grupie kobiet >50. r.ż. u 13 z 14 badanych pacjentek uzyskano w posiewie $P$. acnes (92,9\%); ze względu na brak dodatkowych informacji klinicznych nie analizowano podobnych zależności.

Według danych literaturowych zmiany trądzikowe są zlokalizowane w okolicach obfitujących w gruczoły łojowe, najczęściej na skórze twarzy (w ok. 99\%). Nieco rzadziej wykwity skórne występują na klatce piersiowej, plecach czy kończynach [10]. Potwierdzają to także własne wyniki. Najwięcej posiewów wykonano ze skóry twarzy (302), mniej ze skóry ramion i klatki piersiowej (132) oraz pleców (36). Odwrotnie jednak kształtował się odsetek dodatnich posiewów P. acnes: 94,4\% ze skóry pleców, 84,8\% z klatki piersiowej, $82,5 \%$ z twarzy.

Podstawą skutecznej terapii przeciwtrądzikowej jest odpowiednio dobrana metoda leczenia, często opierająca się na długotrwałym stosowaniu preparatów miejscowych, a w cięższych postaciach na leczeniu doustnym. Głównym założeniem terapii miejscowej jest zahamowanie nadmiernej keratynizacji przewodów wyprowadzających gruczołów łojowych oraz zmniejszenie odczynu zapalnego skóry. Zalecane jest połączenie antybiotykoterapii miejscowej (erytromycyna, klindamycyna) z jednoczesnym stosowaniem innych preparatów, np. nadtlenku benzoilu, lecz nie dłużej niż przez 12 tygodni. Brak efektu klinicznego w postaci ustąpienia zmian zapalnych czy nasilona postać choroby są wskazaniem do zmiany leku stosowanego zewnętrznie lub wdrożenia antybiotykoterapii doustnej. W Polsce rekomendowane leki doustne to przede wszystkim tetracykliny i makrolidy, przy czym ze względu na wiele działań niepożądanych tetracyklin druga grupa leków jest obecnie wyłącznie zarezerwowana dla dzieci poniżej 12. r.ż., kobiet w ciąży czy matek karmiących [21]. Terapia ogólna, poparta miejscowym stosowaniem preparatów z grupy retinoidów lub kwasu azelainowego, zapobiega nawrotom choroby i jest skuteczna u ok. 80-90\% pacjentów [6].

Od wielu lat antybiotykoterapia była podstawą leczenia trądziku, jednak już w latach 80. XX w. w USA i Wielkiej Brytanii ukazało się wiele doniesień o pojawieniu się szczepów opornych na standardowo stosowane leki [22, 23]. Obecnie największym problemem jest narastanie oporności na antybiotyki stosowane miejscowo, głównie erytromycynę i klindamycynę, rzadziej na doustne tetracykliny [24]. Częstość występowania tego zjawiska jest zróżnicowana i wciąż stanowi przedmiot badań w różnych krajach. W badaniach przeprowadzonych w Hongkongu oporność na klindamycynę stwierdzono u 53,5\% szczepów, na erytromycynę u 20,9\%, zaś na tetracyklinę i doksycyklinę u 16,3\% [25]. Nieporównywalnie niższy odsetek izolatów opornych na klindamycynę (3,2\%) uzyskali Song i wsp. [26]. Badania kolumbijskiego zespołu raportują odsetek szczepów opornych na erytromycynę na poziomie $35 \%$, na klindamycynę $15 \%$, zaś na tetracyklinę i doksycyklinę na poziomie 8\% i 9\% [12]. Podobnie badania przeprowadzone w Wielkiej Brytanii w latach 1991-2000 wskazały erytromycynę jako antybiotyk o najwyższym odsetku oporności, sięgającym 58\%, klindamycynę na poziomie 50\%. Niższy odsetek (30\%) zanotowano w przypadku tetracykliny, zaś oporności na doksycyklinę nie określano [27]. Odmienne wyniki uzyskano 
w Danii, gdzie najwyższy odsetek szczepów opornych zanotowano w przypadku klindamycyny - 15,8\%, niższy na tetracyklinę - 9,6\%, a najniższy na ery tromycynę - 8,8\% [28]. Własna analiza lekowrażliwości izolowanych szczepów obejmowała cztery antybiotyki powszechnie stosowane w leczeniu trądziku w Polsce: erytromycynę, klindamycynę, tetracyklinę i doksycyklinę. Wszystkie szczepy okazały się wrażliwe na doksycyklinę i w 98,2\% wrażliwe także na tetracyklinę. Natomiast odnotowano identyczną, nie mniej niepokojąco narastającą oporność na erytromycynę i klindamycynę, od 29,6\% w $2010 \mathrm{r}$. do $48,7 \%$ w $2014 \mathrm{r}$.

Skutki kliniczne narastającej oporności wśród szczepów P. acnes są trudne do oszacowania, choć ukazały się prace, raportujące gorsze efekty antybiotykoterapii u osób, u których doszło do transmisji szczepów opornych od innych pacjentów [29, 30]. Pewny jest fakt, że rosnąca lekooporność staje się coraz większym problemem współczesnej dermatologii. Z tego względu Polskie Towarzystwo Dermatologiczne w oparciu o wytyczne American Academy of Dermatology i Global Alliance to Improve Outcome in Acne Group rekomenduje stosowanie antybiotyków miejscowych przez czas nie dłuższy niż 3 miesiące, a w przypadku antybiotyków doustnych nie dłużej niż 6 miesięcy, a także podkreśla niecelowość prowadzenia monoterapii zarówno w leczeniu miejscowym, jak i ogólnym [10].

\section{WNIOSKI}

Trądzik wciąż pozostaje jedną z głównych chorób skóry u młodzieży oraz u osób dorosłych. Pomimo coraz większych możliwości terapeutycznych narastająca antybiotykooporność szczepów $P$. acnes stwarza wiele trudności w przewidywaniu skutków klinicznych leczenia. Zmusza to lekarzy do dalszego poszukiwania racjonalnych metod terapii, indywidualnego podejścia do pacjenta oraz do uważnego śledzenia bieżących doniesień naukowych, także w zakresie wrażliwości/oporności szczepów P. acnes. Wykonanie badania mikrobiologicznego wydzieliny ze zmiany trądzikowej i określenie lekowrażliwości szczepu może ułatwić podjęcie decyzji terapeutycznej i doprowadzić do uniknięcia powikłań związanych z działaniem niepożądanym antybiotyku.

\section{PIŚMIENNICTWO}

1. Braun-Falco O, Plewig G, Wolff HH, Burdgdorf WHC. Dermatologia. Lublin: Wyd. Czelej; 2004.

2. Plewig G, Kligman AM. Acne and rosacea. Berlin: Wyd. Springer; 1993.

3. Adamski Z, Kaszuba A. Dermatologia dla kosmetologów. Wrocław: Wyd. Elsevier Urban \& Partner; 2010. p. 54-8.

4. Gollnick H, Cunliffe W, Berson D, Dreno B, Finlay A, Leyden JJ, et al. Management of acne: a report from a Global Alliance to Improve Outcomes in Acne. J Am Acad Dermatol 2003;49:S1-37.

5. Krasowska D. Trądzik. Diagnostyka i leczenie. Lublin: Wyd. Czelej; 2009. p. 115-70.

6. Simonart T, Dramaix M. Treatment of acne with topical antibiotics: lessons from clinical studies. Br J Dermatol 2005;153:395-403.
7. European Committee on Antimicrobial Susceptibility Testing. Breakpoints tables for interpretation of MICs and zones diameters. Version 5.0, 2015. http://www.eucast.org (28.03.2017).

8. Jeremy AH, Holland DB, Roberts SG, Thomson KF, Cunliffe WJ. Inflammatory events are involved in acne lesion initiation. J Invest Dermatol 2003;121:20-7.

9. Tałasiewicz K, Ołdakowska A, Szczerkowska-Dobosz A. Evaluation of knowledge about acne vulgaris among a selected population of adolescents of Tricity schools. Post Derm Alergol 2012;29(6):417-20.

10. Szepietowski J, Kapińska-Mrowiecka M, Kaszuba A, Langner A, Placek W, Wolska H, et al. Trądzik zwyczajny: patogeneza i leczenie. Konsensus Polskiego Towarzystwa Dermatologicznego. Przegl Dermatol 2012;99:649-73.

11. Goodman GJ. Patofizjologia blizn potrądzikowych - krótki opis mechanizmu ich powstawania. Dermatol Estet 2002;1:22-8.

12. Mendoza N, Hernandez PO, Tyring SK, Haitz KA, Motta A. Antimicrobial susceptibility of Propionibacterium acnes isolates from acne patients in Colombia. Int J Dermatol 2013;52:688-92.

13. Poli F, Dreno B, Verschoore M. An epidemiological study of acne in female adults: results of a survey conducted in France. J Eur Acad Dermatol Venereol 2001;15:541-5.

14. Khunger N, Kumar C. A clinico-epidemiological study of adult acne: is it different from adolescent acne? Indian J Dermatol Venereol Leprol 2012;78:335-41.

15. Goulden V, Stables GI, Cunliffe WJ. Prevalence of facial acne in adults. J Am Acad Dermatol 1999;41:557-80.

16. Collier CN, Harper JC, Cafardi JA, Cantrell WC, Wang W, Foster KW, et al. The prevalence of acne in adults 20 years and older. J Am Acad Dermatol 2008;58:56-9.

17. McConnell RC, Fleischer AB Jr, Williford PM, Feldman SR. Most topical tretinoin treatment is for acne vulgaris through the age of 44 years: an analysis of the National Ambulatory Medical Care Survey, 1990-1994. J Am Acad Dermatol 1998;38:221-6.

18. Dumont-Wallon G, Dréno B. Specificity of acne in women older than 25 years. Presse Med 2008;37:585-91.

19. Rivera R, Guerra A. Management of acne in women over 25 years of age. Actas Dermosifiliogr 2009;100:33-7.

20. Szczurek P, Kamińska-Winciorek G, Śpiewak R. Częstość występowania trądziku późnego oraz jego wpływ na jakość życia młodych kobiet. Estetol Med Kosmetol 2012;2(2):58-62. doi: 10.14320/EMK.2012.012.

21. Nast A, Dréno B, Bettoli V, Degitz K, Erdmann R, Finlay AY, et al. European evidence-based (S3) guidelines for the treatment of acne. J Eur Acad Dermatol Venereol 2012;Suppl 1:1-29.

22. Leyden JJ, McGinley KJ, Cavalieri S, Webster GF, Mills OH, Kligman AM. Propionibacterium acnes resistance to antibiotics in acne patients. J Am Acad Dermatol 1983;8:41-5.

23. Dreno B, Thiboutot D, Golnick H, Bettoli V, Kang S, Leyden JJ, et al. Antibiotic stewardship in dermatology: limiting antibiotic use in acne. Eur J Dermatol 2014;24(3):330-4.

24. Bowe WP. Antibiotic resistance and acne: where we stand and what the future holds. J Drugs Dermatol 2014;13(6):66-70.

25. Luk NM, Hui M, Lee HC, Fu LH, Liu ZH, Lam LY, et al. Antibiotic-resistant Propionibacterium acnes among acne patients in a regional skin centre in Hong Kong. J Eur Acad Dermatol Venereol 2013;27:31-6.

26. Song M, Seo SH, Ko HC, Oh CK, Kwon KS, Chang CL, et al. Antibiotic susceptibility of Propionibacterium acnes isolated from acne vulgaris in Korea. J Dermatol 2011;38:667-73.

27. Coates P, Vyakrnam S, Eady EA, Jones CE, Cove JH, Cunliffe WJ. Prevalence of antibiotic-resistant propionibacteria on the skin of acne patients: 10 -year surveillance data and snapshot distribution study. Br J Dermatol 2002;146:840-8.

28. Lomholt HB, Kilian M. Clonality and anatomic distribution on the skin of antibiotic resistant and sensitive Propionibacterium acnes. Acta Derm Venereol 2014;94:534-8.

29. Thiboutot D, Gollnick H, Bettoli V, Dréno B, Kang S, Leyden JJ, et al. New insights into the management of acne: an update from the Global Alliance to Improve Outcomes in Acne group. J Am Acad Dermatol 2009;60:S1-50.

30. Eady AE, Cove JH, Layton AM. Is antibiotic resistance is cutaneous propionibacteria clinically relevant?: implications of resistance for acne patients and prescribers. Am J Clin Dermatol 2003;4:813-31. 